\title{
Resposta de cultivares de Brachiaria brizantha a doses de biofertilizantes de aves
}

\section{Response of Brachiaria brizantha at doses of poultry biofertilizers}

\author{
Patrícia Paiva da Silva', Rafael Silva Ferreira', Paulo Eduardo Teodoro1*, \\ Francisco Eduardo Torres ${ }^{1}$, Gilcelene Medeiros Arima ${ }^{1}$, Nanci Cappi ${ }^{1}$, Larissa Pereira Ribeiro ${ }^{1}$
}

RESUMO: Cada vez mais fertilizantes são importados, fato que faz com que o uso de dejetos tratados seja alternativa econômica e sustentável para a produção de forragens. O objetivo do trabalho foi avaliar o efeito da aplicação de diferentes doses de biofertilizante de aves sobre a produção de forragem de cultivares de Brachiaria brizantha (Hochst.) Stapf. O delineamento experimental utilizado foi o inteiramente casualizado, com quatro repetições, em esquema fatorial. O primeiro fator consistiu nos cultivares Marandu e Piatá de $B$. brizantha, enquanto o segundo fator correspondeu às doses de biofertilizante de aves $\left(0,50,100\right.$ e $\left.150 \mathrm{~m}^{3} \mathrm{ha}^{-1}\right)$. Foram avaliados os seguintes caracteres morfométricos: altura de planta (AP), comprimento da lâmina foliar (CLF), largura da lâmina foliar (LLF) aos 15, 30, 45 e 60 dias após a emergência (DAE), e massa de matéria verde e seca (MV e MS, respectivamente) das folhas, colmo e raízes aos 60 DAE. A dose de $50 \mathrm{~m}^{3} \mathrm{ha}^{-1}$ de biofertilizante de aves promoveu incrementos nas características morfométricas e produção de forragem dos cultivares Marandu e Piatá, enquanto doses de 100 e $150 \mathrm{~m}^{3}$ ha $^{-1}$ ocasionaram a morte desses cultivares.

PALAVRAS-CHAVE: avicultura; cultivar Marandu; cultivar Piatá; pastagem.
ABSTRACT: Fertilizers are more and more imported, and such a fact makes so that the use of treated waste is an economical and sustainable alternative for fodder production. The objective of this study was to evaluate the effect of different doses of bio-fertilizer from birds on forage yield of Brachiaria brizantha (Hochst.) Stapf. The experimental design was completely randomized, with four replications in a factorial arrangement. The first factor consisted of the cultivars Marandu and Piata, while the second factor corresponded to doses of biofertilizer from birds $\left(0,50,100\right.$ and $\left.150 \mathrm{~m}^{3} \mathrm{ha}^{-1}\right)$. The following morphometric aspects were evaluated: plant height $(\mathrm{PH})$, leaf blade length (LBL), leaf blade width (LBW) at 15, 30, 45 and 60 days after emergence (DAE) and green and dry matter (GM and DM, respectively), stem and roots at $60 \mathrm{DAE}$. The dose of $50 \mathrm{~m}^{3} \mathrm{ha}^{-1}$ of bio-fertilizers from birds promoted increasing morphometric characteristics and forage yield of cultivars Marandu and Piatá, while doses of 100 and $150 \mathrm{~m}^{3} \mathrm{ha}^{-1}$ caused the death of these cultivars.

KEYWORDS: aviculture; Marandu cultivar; Piatá cultivar; pasture.

\footnotetext{
'Universidade Estadual de Mato Grosso do Sul (UEMS) - Aquidauana (MS), Brasil.

*Autor correspondente: eduteodoro@hotmail.com

Recebido em: 04/12/2012. Aceito em: 07/07/2014
} 
O problema ambiental que vem recebendo atenção especial nos últimos anos, não apenas no que se refere à avicultura, mas à produçáo animal em geral, é o alto potencial de emissáo de gases de efeito estufa proveniente da degradação dos dejetos em locais inapropriados. Segundo a UnfCCC (2006), 20\% das emissōes mundiais de gases de efeito estufa são provenientes das atividades agropecuárias, sendo o metano (produzido durante a degradaçáo da matéria orgânica em meio anaeróbio) e o óxido nitroso (produzido em meios anaeróbios utilizando os compostos nitrogenados de natureza orgânica ou inorgânica) os principais gases envolvidos.

No cenário da avicultura de postura comercial, as novas tecnologias relacionadas às instalaçôes rurais dão ao setor a oportunidade de aumentar o número de aves alojadas, mas, como consequência, isso promove aumento na produçáo de dejetos (LANA et al., 2010). Esta produçáo gera, em mesma proporção, uma grande quantidade de poluentes ambientais, causados pela falta de tratamento adequado de resíduos. Assim, evidencia-se a necessidade de dar destino adequado às excretas das aves, gerando, em adição, fertilizante potencial para a adubação de áreas agricultáveis, reduzindo possíveis impactos ambientais que poderão ser causados por deposiçóes inadequadas desses resíduos.

O uso de biofertilizantes, produto de biodigestores, como fonte de nutrientes para pastagens e outras culturas, contribui para a minimizaçáo do efeito poluidor das excretas dos animais. Além disso, torna-se econômico em relação ao produto comercial ao melhorar a estrutura do solo, devido à grande incorporação de matéria orgânica, devolvendo nutrientes que foram consumidos pela planta juntamente com a fixação de uma nova população de micro-organismos (Moraes et al., 2006).

Segundo Mondardo et al. (2009), os resíduos orgânicos sáo considerados insumos de baixo custo e de alto retorno econômico para a agropecuária. A economia se caracteriza não só pelo fato de ser um recurso disponível na propriedade, como também pela possibilidade de tratar esses resíduos com baixo custo. Após sua mineralização, podem ser utilizados como adubo orgânico. Nesse contexto, o objetivo do trabalho foi avaliar o efeito da aplicação de diferentes doses de biofertilizante de aves sobre as características morfométricas e a produção de forragem de cultivares de Brachiaria brizantha (Hochst.) Stapf.

O experimento foi instalado de março a junho de 2011, no setor de Fitotecnia da Universidade Estadual de Mato Grosso do Sul - Unidade Universitária de Aquidauana. O solo da área foi classificado como Argissolo VermelhoAmarelo distrófico de textura arenosa, com as seguintes características na camada de $0-0,20 \mathrm{~m}: \mathrm{pH}\left(\mathrm{CaCl}_{2}\right)=4,87 ; \mathrm{Al}$ trocável $\left(\mathrm{cmol}_{\mathrm{c}} \mathrm{dm}^{-3}\right)=0,10 ; \mathrm{Ca}+\mathrm{Mg}\left(\mathrm{cmol}_{\mathrm{c}} \mathrm{dm}^{-3}\right)=4,60$;

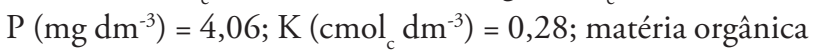
$\left(\mathrm{g} \mathrm{dm}^{-3}\right)=20,46 ; \mathrm{V}(\%)=58,16$.
O delineamento experimental utilizado foi o inteiramente casualizado, com quatro repetiçóes, em esquema fatorial. O primeiro fator consistiu nos cultivares Marandu e Piatá de B. brizantha, enquanto o segundo fator correspondeu às doses de biofertilizante de aves $\left(0,50,100\right.$ e $\left.150 \mathrm{~m}^{3} \mathrm{ha}^{-1}\right)$. O biofertilizante de aves de postura ficou retido 55 dias em biodigestores de bancada, apresentando $3,44 \mathrm{mg} \mathrm{kg}^{-1}$ de nitrogênio total e $5,3 \mathrm{mg} \mathrm{dm}^{-3}$ de fósforo.

Os tratamentos foram dispostos em vasos plásticos com capacidade de $5 \mathrm{~L}$, e acondicionados em estufa agrícola com tela termorrefletora de $50 \%$ de sombreamento. A adubaçáo de base consistiu de $15 \mathrm{~g}$ de superfosfato simples (18\% de $\mathrm{P}_{2} \mathrm{O}_{5}, 20 \%$ de $\mathrm{CaO}, 12 \%$ de S) em cada vaso. A aplicação de biofertilizante foi parcelada, ocorrendo três dias antes da semeadura e 15 dias após a emergência (DAE), com auxílio de uma proveta de $0,5 \mathrm{~L}$. Os vasos foram irrigados com água diariamente pela manhã, de acordo com a evapotranspiração média do ambiente.

Foram avaliados os seguintes caracteres morfométricos: altura de planta (AP), comprimento da lâmina foliar (CLF), largura da lâmina foliar (LLF) aos 15, 30, 45 e 60 DAE, e massa de matéria verde e seca (MV e MS, respectivamente) das folhas, colmo e raízes aos $60 \mathrm{DAE}$. As variáveis AP, CLF e LLF foram determinadas utilizando-se régua graduada em centímetros, sendo medidas as quatro plantas da unidade experimental. Para AP, considerou-se a altura medida do nível do solo até a inserção da primeira folha da planta completamente desenvolvida. Para a variável CLF, considerou-se o comprimento medido da base do limbo até o seu ápice. A massa de matéria seca foi determinada após secagem das amostras em estufa, com circulação forçada a $65^{\circ} \mathrm{C}$ até peso constante.

As variáveis analisadas foram inicialmente submetidas aos testes de Shapiro-Wilk, para verificar a normalidade dos resíduos, e de Bartlett, para testar a homogeneidade entre as variâncias. Posteriormente, os dados foram submetidos à análise de variância e as médias foram submetidas ao teste de Tukey, com nível de $1 \%$ de probabilidade.

Para todas variáveis morfométricas, houve significância $(\mathrm{p}<0,01)$ para o fator dose de biofertilizante (D), idade da planta (I) e a interação entre ambos (D x I) (Tabela 1). Estes resultados corroboram os obtidos por FerReira et al. (2013), que, ao avaliarem a influência da aplicação de biofertilizante suíno sobre a produção de $B$. brizantha, não constataram diferenças entre os cultivares Marandu e Piatá. Esses autores também evidenciaram o acréscimo da AP, CLF e LLF, atribuindo tais resultados à correta nutrição das plantas.

Aos 15 e 30 DAE, observou-se que a testemunha apresentou um maior desenvolvimento em comparação às demais doses. Entretanto, aos 45 e 60 DAE os cultivares que se desenvolveram melhor foram os que receberam o tratamento de $50 \mathrm{~m}^{3}$ $\mathrm{ha}^{-1}$ de biofertilizante. Isso se deve ao fato de que o composto orgânico fornece $\mathrm{N}$ lentamente às plantas, principal nutriente 
Tabela 1. Análise de variância e valores médios da altura de planta, comprimento e largura da lâmina foliar de cultivares de Brachiaria brizantha sp. submetidos a diferentes doses de biofetilizante de aves.

\begin{tabular}{lccc} 
& AP & CLF & LLF \\
& \multicolumn{3}{c}{ cm } \\
Cultivar (C) & $3821,89^{\text {ns }}$ & $12,91^{\text {ns }}$ & $0,29^{\text {ns }}$ \\
\hline Dose (D) & $660,44^{*}$ & $893,28^{*}$ & $13,58^{*}$ \\
\hline Idade (I) & $975,39^{*}$ & $869,88^{*}$ & $25,91^{*}$ \\
\hline DxC & $171,65^{\text {ns }}$ & $52,94^{\text {ns }}$ & $0,81^{\text {ns }}$ \\
\hline CxI & $997,60^{\text {ns }}$ & $99,12^{\text {ns }}$ & $0,68^{\text {ns }}$ \\
\hline DxI & $1042,24^{*}$ & $1212,94^{*}$ & $2,94^{*}$ \\
\hline DxCxl & $186,98^{\text {ns }}$ & $36,91^{\text {ns }}$ & $0,15^{\text {ns }}$ \\
\hline Idade (dias) & & & \\
\hline 15 & $25,09 \mathrm{~d}$ & $22,39 \mathrm{~d}$ & $0,84 \mathrm{~d}$ \\
\hline 30 & $40,99 \mathrm{c}$ & $41,19 \mathrm{c}$ & $1,39 \mathrm{c}$ \\
\hline 45 & $60,12 \mathrm{~b}$ & $48,91 \mathrm{~b}$ & $1,49 \mathrm{~b}$ \\
\hline 60 & $71,85 \mathrm{a}$ & $55,18 \mathrm{a}$ & $1,60 \mathrm{a}$ \\
\hline Dose $\left(\mathrm{m}^{3}\right.$ ha $\left.^{-1}\right)$ & & & \\
\hline 0 & $50,84 \mathrm{~b}$ & $40,45 \mathrm{~b}$ & $1,20 \mathrm{~b}$ \\
\hline 50 & $54,25 \mathrm{a}$ & $45,67 \mathrm{a}$ & $1,39 \mathrm{a}$ \\
\hline 100 & $0,00 \mathrm{c}$ & $0,00 \mathrm{c}$ & $0,00 \mathrm{c}$ \\
\hline 150 & $0,00 \mathrm{c}$ & $0,00 \mathrm{c}$ & $0,00 \mathrm{c}$ \\
\hline
\end{tabular}

Médias sequidas por letras iquais na mesma coluna não diferem entre si pelo Teste de Tukey, a $1 \%$ de probabilidade. ${ }^{\text {ns }} e^{*}$ : não significativo e significativo a $1 \%$ de probabilidade, respectivamente, pelo Teste $F$. AP: altura de planta, CLF: comprimento da lâmina foliar, LLF: largura da lâmina foliar. demandado pelas forrageiras, evitando perdas deste nutriente por lixiviação. Para Augusto (2005), deve-se destacar o efeito do composto orgânico como agente condicionador do solo, melhorando suas características físicas, como plasticidade, porosidade, além da capacidade de retenção de água pelo solo e melhoria na estrutura do solo, permitindo maior penetração de ar.

As doses de 100 e $150 \mathrm{~m}^{3} \mathrm{ha}^{-1}$ causaram a morte das plantas, fato ocorrido devido ao possível excesso de nitrogênio presente no fertilizante orgânico. De acordo com KieHL (1985), o elevado teor de nitrogênio em biofertilizante de aves pode exercer efeito tóxico sobre uma determinada cultura, sendo importante avaliar suas dosagens para uma recomendação segura para a produção de forrageiras.

A dose de $50 \mathrm{~m}^{3} \mathrm{ha}^{-1}$ de biofertilizante de aves proporcionou incremento $(\mathrm{p}<0,01)$ na produção de MV e MS das folhas, colmo e raiz em relação à testemunha (Tabela 2). Resultados semelhantes foram obtidos por Ferreira et al. (2013) e LANA et al. (2010), que verificaram efeito positivo da aplicação de biofertilizante suíno e de aves, respectivamente, sobre a produção de forragem dos cultivares Marandu e Piatá. Isso possivelmente ocorreu na presença adequada de nutrientes, sobretudo o nitrogênio, pois, de acordo com CECATO et al. (1996), tal nutriente acelera a formação e o crescimento de novas folhas e melhora o vigor de rebrota, incrementando a recuperação das forrageiras após o corte.

Tabela 2. Análise de variância e valores médios da massa de matéria verde fresca e seca de folhas, colmo e raiz de cultivares de Brachiaria brizantha sp. submetidos a diferentes doses de biofetilizante de aves.

\begin{tabular}{lrrrrrr} 
& \multicolumn{2}{c}{ Folhas } & \multicolumn{2}{c}{ Colmo } & & Raiz \\
\cline { 2 - 7 } Doses & $M V$ & MS & MV & MS & MV & MS \\
\hline C & $2,04^{\text {ns }}$ & $0,11^{\text {ns }}$ & $1,72^{\text {ns }}$ & $0,02^{\text {ns }}$ & $1,02^{\text {ns }}$ & $0,59^{\text {ns }}$ \\
\hline D & $337,19^{*}$ & $209,62^{*}$ & $449,12^{*}$ & $153,04^{*}$ & $148,05^{*}$ & $60,02^{*}$ \\
\hline CxD & $2,44^{\text {ns }}$ & $0,51^{\text {ns }}$ & $2,03^{\text {ns }}$ & $1,75^{\text {ns }}$ & $1,86^{\text {ns }}$ & $2,64^{\text {ns }}$ \\
\hline O & $21,26 \mathrm{~b}$ & $7,30 \mathrm{~b}$ & $22,27 \mathrm{~b}$ & $7,40 \mathrm{~b}$ & $28,712 \mathrm{~b}$ & $8,00 \mathrm{~b}$ \\
\hline 50 & $116,35 \mathrm{a}$ & $24,90 \mathrm{a}$ & $142,51 \mathrm{a}$ & $21,58 \mathrm{a}$ & $55,30 \mathrm{a}$ & $13,65 \mathrm{a}$ \\
\hline 100 & $0,00 \mathrm{c}$ & $0,00 \mathrm{c}$ & $0,00 \mathrm{c}$ & $0,00 \mathrm{c}$ & $0,00 \mathrm{c}$ & $0,00 \mathrm{c}$ \\
\hline 150 & $0,00 \mathrm{c}$ & $0,00 \mathrm{c}$ & $0,00 \mathrm{c}$ & $0,00 \mathrm{c}$ & $0,00 \mathrm{c}$ & $0,00 \mathrm{c}$ \\
\hline
\end{tabular}

Médias seguidas por letras iguais na mesma coluna não diferem entre si pelo Teste de Tukey, a $1 \%$ de probabilidade. ${ }^{\text {ns }}$ e ${ }^{*}$ : não significativo e significativo a $1 \%$ de probabilidade, respectivamente pelo Teste $\mathrm{F}$.

MV: massa de matéria verde fresca, MS: massa de matéria verde seca



\section{REFERÊNCIAS}

AUGUSTO, K.V.Z. Manejo de dejetos em granjas de postura comercial. Revista Avicultura Industrial, v. 1134, n.5, p.5456, 2005.

CECATO, V.; GOMES, L.H.; ASSIS, M.A.; SANTOS, G.T.; BETT, V. Avaliação de cultivares do gênero Cynodon. In: REUNIÃO ANUAL DA SOCIEDADE BRASILEIRA DE ZOOTECNIA, 1996, Fortaleza, CE. Anais. Fortaleza: SBZ. 1996. p.114-116.
FERREIRA, R.S.; SILVA JUNIOR, C.A.; TEODORO, P.E.; SILVA, P.P.; ARIMA, G.M.; CAPPI, N.; TORRES, F.E. Effect of different doses of swine biofertilizer in the development and production of cultivars of Brachiaria brizantha. Journal of Agronnomy, v.12, n. 1, p.53-58, 2013.

KIEHL, E.J. (Ed.). Fertilizantes orgânicos. Piracicaba: Agronômica Ceres, 1985. 492p. 
LANA, R.M.Q.; ASSIS, D.F.; SILVA, A.A. LANA, A.M.Q.; GUIMARÃES, E.C.; BORGES, E.N. Alterações na produtividade e composição nutricional de uma pastagem após segundo ano de aplicação de diferentes doses de cama de frango. Bioscience Journal, v.26, n.2, p.249-256, 2010.

MORAES, B.E.R.; MOURA, G.S.A.; PRADO, P.P.; BENEDETTI, E. Potencialidades do uso de cama de frango na recuperação de pastagens degradadas de Brachiaria decumbens. Veterinária Notícias, v.12, n.2, p.127, 2006.
MONDARDO, D.; CASTAGNARA, D.D.; BELLON, P.P.; MEINERZ, C.C.; OLIVEIRA, P.S.R.; NERES, M. Adubação nitrogenada da Brachiaria brizantha com dejeto líquido suíno. Revista Brasileira de Agroecologia, v.4, n.2, p.3265-3269, 2009.

UNFCCC. United Nations framework convention on climate change. Kyoto protocol, 1998. Disponível em: <http:// unfccc.int/resource/docs/convkp/kpeng.pdf $>$. Acesso em 1 jan. 2012. 